\title{
Assessment of Novel Synthetized Nanozirconium Tungstovanadate as Cation Exchanger for Lead Ion Decontamination
}

\author{
M. F. Elkady, ${ }^{1}$ E. M. El-Sayed, ${ }^{1}$ H. A. Farag, ${ }^{2}$ and A. A. Zaatout $^{2}$ \\ ${ }^{1}$ Fabrication Technology Department, Advanced Technology and New Materials Research Institute (ATNMRI), \\ City of Scientific Research and Technology Applications, Alexandria 21934, Egypt \\ ${ }^{2}$ Chemical Engineering Department, Faculty of Engineering, Alexandria University, Alexandria 21544, Egypt
}

Correspondence should be addressed to M. F. Elkady; maroelkady@yahoo.com

Received 19 October 2013; Accepted 12 December 2013; Published 8 January 2014

Academic Editor: Arun Kumar

Copyright (C) 2014 M. F. Elkady et al. This is an open access article distributed under the Creative Commons Attribution License, which permits unrestricted use, distribution, and reproduction in any medium, provided the original work is properly cited.

A novel nanozirconium tungstovanadate that was assigned as a cation exchanger was synthetized using sol-gel preparation technique. The response of synthesis parameter variation on the properties of the produced ion exchanger was elucidated. The reactant molar ratio, gelation temperature, and $\mathrm{HCl}$ concentration have been optimized to attain cation exchanger with high ion exchange capacity and lead ion sorption. The most proper prepared sample has been chemically and physically characterized using different techniques. The ion exchange capacity of this sample was $2.5 \mathrm{meq} / \mathrm{g}$ and it recoded $96 \%$ lead ion sorption. The effects of the different processing parameters that affect lead sorption process have been investigated by a single factor method. Langmuir and Freundlich isotherm models were applied to the experimental data to examine the lead uptake mechanism.

\section{Introduction}

Growing attention is being given to the potential health hazard posed by heavy metals in the environment. The major sources of heavy metal contamination are considered to be from industries such as lead from petrol based industries; chromium from chrome plating, petroleum refining, leather, tanning, wood preserving, textile manufacturing, and pulp processing industries; zinc from paint, rubber, dye, wood preservatives, ointments, and electroplating industries; and nickel from galvanized, paint and powder batteries processing industries [1]. Although this issue has been studied for many years, effective treatment options are still limited. Chemical precipitation, adsorption, reverse osmosis, and ion exchange processes are the most common techniques utilized for removing heavy metals ions from dilute aqueous streams [2]. Lead is one of the most dangerous pollutants; even at low concentrations, it is extremely toxic, causing brain damage in children [3]. The ion exchange separation technique is characterized over the other separation techniques by its simplicity and because it is cheap and not energy consumable. Accordingly, the ion exchange process represents the most suitable technique for lead ion separation from polluted wastewaters. There are various types of ion exchange materials that are suitable to be utilized for the ion exchange process from either the organic or inorganic nature. Recently, synthetic inorganic ion exchangers have gained much attention owing to their high selectivity for certain elements, good sorption kinetics and specially their greater stability to heat, ionizing radiation and different chemical media. Heteropolyacid salts are special compounds with two or more different types of anions condensed together which can be used as inorganic ion exchangers. This group of exchangers is derived from 12-heteropolyacids of general formula $\mathrm{H}_{n} \mathrm{XY}_{12} \mathrm{O}_{40} \cdot n \mathrm{H}_{2} \mathrm{O}$ where $\mathrm{X}$ may be $\mathrm{P}, \mathrm{As}, \mathrm{Si}, \mathrm{B}$, or Ce and $\mathrm{Y}$ may be one of the elements such as Mo, W, or $\mathrm{V}$. The heteropolyacid salts of polyvalent metals are of great interest because of their ion exchange character, as they are superior to single insoluble salts of these metals. It is possible to vary their compositions and change their selectivity to a particular ion. Ammonium phosphotungstate and ammonium molybdophosphate were probably the first 
materials of this type, which had been studied as ion exchangers [4]. Since then the ion exchange behaviour, analytical application, and synthesis of several zirconium compounds such as zirconium(IV) tungstomolybdate [5], zirconium(IV) tungstoiodophosphate [6], zirconium(IV) iodovanadate [7], zirconium(IV) selenomolybdate [8], zirconium titanium phosphate [9], zirconium(IV) zirconium(IV) iodotungstate [10], and zirconium(IV) antimonotungstate [11] have been extensively studied. These inorganic ion exchangers were found to show relatively increased ion exchange capacity and selectivity and played a prominent role in water processing in the chemical and nuclear industries $[11,12]$. In this regard an inorganic heteropoly acid salt of zirconium based compound will be synthetized in nanoscale using the sol-gel preparation technique. This investigation will deal with optimization of the different factors that affect the nanozirconium tungstovanadate properties to attain nanopowder ion exchanger with high IEC with high lead ion sorption affinity. Moreover, the influence of the different parameters affecting the lead ion sorption process onto the prepared cation exchanger will be monitored. Finally, the equilibrium lead ions sorption data will be modelled as an attempt to determine the sorption process mechanism.

\section{Materials and Methods}

2.1. Reagents and Instrumentation. Zirconium oxychloride (purity 99\%, AVONCHEM, UK, Germany), ammonium metavanadate (purity 96\%, Pratap Chemical Industries Pvt. Ltd., India), and sodium tungstate (purity 99\%, Pratap Chemical Industries Pvt. Ltd., India) have been used as the raw materials for the synthesis of zirconium(IV) tungstovanadate. Solutions of the various materials have been prepared in demineralized water (DMW). All these materials/reagents were mainly of analytical grade. $\mathrm{pH}$ measurements were performed using a single electrode digital $\mathrm{pH}$-meter (Denver Instrument Co., USA). Magnetic stirrer model-526 (J.P. Selecta Co., Spain) was used during the preparation procedure for sol-gel technique with the aid of identical magnets. An electron microscope (JEOL JSM 6360LA, Japan) has been used for studying morphological properties of the synthesized materials. IR studies were made using a FTIR (Shimadzu FTIR-8400 S, Japan). For studying the thermal properties, a thermogravimetric analyser TGA (Shimadzu TGA-50, Japan) and DSC (Shimadzu DSC-60A, Japan) were used. X-ray diffractometer (Shimadzu-7000, USA) was used for determining the X-ray diffraction pattern of the prepared materials. Thermal stabilities of the different prepared materials have been studied using muffle furnace (Carbolite, Aston Lane, England).

\subsection{Synthesis of ZWV Ion Exchanger Using Sol-Gel Tech-} nique. Different samples of zirconium tungstovanadate were prepared by the sol-gel method through addition of mixture of $50 \mathrm{~mL}$ ammonium metavanadate and $50 \mathrm{~mL}$ sodium tungstate into $150 \mathrm{~mL}$ zirconium oxychloride solution in different molar ratios in presence of $\mathrm{HCl}$ gradually with continuous stirring of the mixture in order to get a stable product with good ion exchange properties using magnetic stirrer. After the addition was complete a fine yellow precipitate appeared. The reaction mixture was diluted to $1 \mathrm{~L}$ and allowed to settle for $24 \mathrm{~h}$ for complete digestion [13]. The supernatant liquid was decanted and gels were filtered by suction using vacuum pump (Ismatec, Switzerland) and the excess acid was washed thoroughly with hot water. The washed precipitate was then dried by gentle heating at $40^{\circ} \mathrm{C}$. Then the product is grounded and immersed in $1 \mathrm{M}$ nitric acid for 1 day with gentle stirring in order to transform the ion exchanger to its hydrogen form. In order to optimize the preparation conditions of zirconium (IV) tungstovanadate using sol-gel technique, the effect of hydrochloric acid concentration (0$0.5 \mathrm{M})$, gelation temperature $\left(25-80^{\circ} \mathrm{C}\right)$, and molar ratio of the reactants were studied. The different prepared samples of the ion exchanger will be screened on the basis of $\mathrm{Na}^{+}$ion exchange capacity and lead affinity and the best sample will be selected for detailed studies.

\subsection{Chemical Characterization of the Prepared Nanozirconium Tungstovanadate Ion Exchangers}

2.3.1. Ion Exchange Capacity (IEC). The ion exchange capacities of different prepared ion exchangers were determined by acid-base titration [14]. The weighted samples of the ion exchanger in its $\mathrm{H}^{+}$form were soaked in $50 \mathrm{~mL}$ of $1 \mathrm{M} \mathrm{NaCl}$ solution for at least $12 \mathrm{~h}$ with shaking at ambient temperature using orbital shaker (Yellow line Os10 Control, Germany) to exchange protons with sodium ions. The ion exchanged was titrated against a standard solution of $0.1 \mathrm{M} \mathrm{NaOH}$ using phenolphthalein as indicator. The ion exchange capacity (IEC) was calculated using the following equation:

$$
\operatorname{IEC}\left(\frac{\text { mequiv }}{\mathrm{g}}\right)=V_{\mathrm{NaOH}} * \frac{C_{\mathrm{NaOH}}}{W_{d}},
$$

where $V_{\mathrm{NaOH}}, C_{\mathrm{NaOH}}$, and $W_{d}$ are the volume of $\mathrm{NaOH}$ consumed in titration, the concentration of $\mathrm{NaOH}$ solution, and the weight of the dry sample, respectively.

2.3.2. Ion Exchange Capacity for Different Metal Ions. The ion exchange capacity of prepared nanozirconium tungstovanadate for alkali and alkaline earth metal ions was determined by equilibrating $0.25 \mathrm{~g}$ of the exchanger with $50 \mathrm{~mL}$ of $2 \mathrm{M}$ solution of different metal salts. The liberated acid was measured by titration with standard alkali solution [15].

2.3.3. Thermal Effect on IEC. The effect of temperature on the ion exchange capacity of the most efficient prepared nanozirconium tungstovanadate was determined by heating $0.5 \mathrm{~g}$ from the ion exchange material at various temperatures in muffle furnace for $1 \mathrm{~h}$. The $\mathrm{Na}^{+}$ion exchange capacity after cooling the samples at room temperature was determined as mentioned in the ion exchange capacity technique [16].

2.3.4. Chemical Stability. The extent of dissolution of the material in common mineral acids $\left(\mathrm{HCl}, \mathrm{HNO}_{3}\right.$, and $\left.\mathrm{H}_{2} \mathrm{SO}_{4}\right)$, bases $(\mathrm{NaOH}$ and $\mathrm{KOH})$, and organic solvents (acetone, 
benzene, diethyl ether, heptane, acetic acid, and alcohol) was studied. $0.5 \mathrm{~g}$ of ion exchanger was equilibrated with $20 \mathrm{~mL}$ of the solution of interest for $24 \mathrm{~h}$ at room temperature with agitation at $100 \mathrm{rpm}$; the remaining amount of material was filtered and washed by DMW. After removal of excess acid or base, it was dried in oven at $40 \pm 5^{\circ} \mathrm{C}$. The changes in color, weight, and the on exchange capacity of the remaining material were observed [15].

\subsection{Physical Characterization of the Differed Prepared Zirconium (IV) Tungstovanadate Ion Exchangers}

2.4.1. X-Ray Diffraction (XRD). X-ray diffraction pattern of the best prepared ion exchange material was recorded by $\mathrm{X}$-ray diffractometer with $\mathrm{Cu} \mathrm{Ka}$ radiation beam $(\mathrm{l}=$ $0.154060 \mathrm{~nm}$ ) to determine the structure of the ion exchangers, where the finely powdered samples of the ion exchanger were packed into a flat aluminium holder and the X-ray source was a rotating anode operating at $30 \mathrm{kV}$ and $30 \mathrm{~mA}$ with a copper target. Data were collected between $10^{\circ}$ and $80^{\circ}$ in $2 \theta$.

2.4.2. Thermal Analysis (TGA). The measurements of the thermal analysis of the best prepared sample were carried out using thermogravimetric analyzer (Shimadzu TGA-50, Japan) with a heating rate $20^{\circ} \mathrm{C} / \mathrm{min}$ under flow of $\mathrm{N}_{2}$ to avoid thermal oxidation of the powder samples, starting from ambient condition up to $700^{\circ} \mathrm{C}$.

2.4.3. Infrared Spectroscopy (FTIR). The I.R. spectrum of the best prepared ion exchanger was examined using Fourier Transform Infrared Spectrophotometer (Shimadzu FTIR8400 S, Japan). The disc technique using $\mathrm{KBr}$ as a matrix was found to be suitable. In this concern, the ion exchanger was thoroughly mixed with $\mathrm{KBr}$ and the mixture was ground and then pressed with a special press to give a disc of standard diameter. The I.R. spectrum was scanned through a wave length range of $600-4000 \mathrm{~cm}^{-1}$.

2.4.4. Scanning Electron Microscope (SEM). The grounded prepared samples were scanned to identify their structure and estimate the particle diameter at different magnifications using scanning electron microscope (JEOL JSM 6360 LA, Japan). The mean diameter of the grains was determined from the SEM pictures by measuring at least 5 crystals for each formulation using the software image tool.

2.5. Lead Ion Sorption Affinity. The ion exchange efficiency of the prepared samples toward lead ions was tested. The ion exchange efficiency was determined by equilibrating $0.25 \mathrm{~g}$ of the selected cation exchanger sample of zirconium(IV) tungstovanadate in $\mathrm{H}^{+}$form with $100 \mathrm{~mL}$ of $50 \mathrm{ppm}$ lead ion solution for $3 \mathrm{~h}$ with continuous shaking.

2.6. Batch Procedure for Ion Exchange Technique. The experiments were conducted in batch mode using synthesized wastewater which was prepared initially, where lead chloride $\left(\mathrm{PbCl}_{2} \cdot 5 \mathrm{H}_{2} \mathrm{O}\right)$ was dissolved in distilled water to obtain the required lead concentration. These experiments were carried out to validate the effect of contact time $(0-3 \mathrm{hr}), \mathrm{pH}$ $(2-11)$, temperature $\left(25-80^{\circ} \mathrm{C}\right)$, mixing speed $(0-400 \mathrm{rpm})$, initial concentration of the synthesis solution (5-1000 ppm), and the amount of ion exchanger (0.1-5g) on the ion exchange process using the most proper synthetized ion exchanger.

The experiments carried out through mixing a certain amount of ion exchanger in the $\mathrm{H}^{+}$form in a vial with the test solution (typically $100 \mathrm{~mL}$ ) spiked with waste solution. The samples were mixed in shaking incubator till the solid/solution system obtained equilibrium after $3 \mathrm{~h}$. Then the different phases are separated using centrifugation at $6000 \mathrm{rpm}$ for $10 \mathrm{~min}$. The residual lead ion concentration in the solution was analyzed using inductive coupled plasma mass spectrophotometer. All experiments were carried out in duplicate and mean values are presented. The lead ion measurements onto the ICP (ICP-AES, USA) equipment were repeated three times to obtain an accurate lead ion concentration using the multielement test solution. The percentage error in the measurement of lead ion concentration is \pm 0.1 . The mean lead concentration values in the remaining waste solution were obtained and used for calculation of the percentage ions removal onto the prepared nanocation exchange sample. The sorption capacity of the prepared material was calculated using following formula:

$$
q_{e}=\frac{\left(C_{o}-C_{e}\right) V}{m}
$$

where $q_{e}(\mathrm{mg} / \mathrm{g})$ is the equilibrium adsorption capacity, $C_{o}$ and $C_{e}(\mathrm{mg} / \mathrm{L})$ are the initial and equilibrium concentration of lead ions in solution, $V(\mathrm{~L})$ is the solution volume, and $\mathrm{m}(\mathrm{g})$ is the amount of the cation exchanger.

Finally, The Langmuir and Freundlich equilibrium isotherms models were examined to fit the resultant experimental data. The sorption data obtained for equilibrium conditions have been analyzed using the linear forms of these kinds of isotherms.

\section{Result and Discussion}

Different factors that affect the preparation process are optimized to attain heteropoly acid cation exchanger of nanozirconium tungstovanadate that is characterized by its high IEC and prepared in nanoscale. The various synthetized samples of this innovative cation exchanger that was produced using sol-gel technique under varying conditions are investigated in Table 1. It was obvious from this table that sample S6 recorded the highest production yield and the maximum ion exchange capacity, in contrast to sample S2 that attains the minimum IEC. The efficiency of these prepared samples for heavy metal sorption was tested toward lead ion removal and the results are investigated in Figure 1. These results have been used to confirm the ion exchange capacities values that have been calculated previously for each prepared ion exchange sample (Table 1). 
TABLE 1: Effect of synthesis parameters on the ion exchange capacity (IEC) of zirconium tungstovanadate.

\begin{tabular}{|c|c|c|c|c|c|c|}
\hline \multicolumn{7}{|c|}{ (1) Molar ratio of the reactants } \\
\hline Sample & $\begin{array}{c}\text { Zirconium } \\
\text { oxychloride (M) }\end{array}$ & $\begin{array}{c}\text { Sodium } \\
\text { tungstate (M) }\end{array}$ & $\begin{array}{l}\text { Ammonium } \\
\text { metavanadate } \\
\text { (M) }\end{array}$ & $\begin{array}{c}\text { Volume ratio } \\
(\mathrm{v} / \mathrm{v})\end{array}$ & IEC (meq/g) & Yield (g) \\
\hline S1 & 0.1 & 0.1 & 0.1 & $1.5: 1: 1$ & 1.2 & 4.66 \\
\hline S2 & 0.1 & 0.2 & 0.1 & $1.5: 1: 1$ & 1.1 & 2.1 \\
\hline S3 & 0.1 & 0.1 & 0.2 & $1.5: 1: 1$ & 1.15 & 2.15 \\
\hline S4 & 0.2 & 0.1 & 0.2 & $1.5: 1: 1$ & 1.9 & 6.2 \\
\hline S5 & 0.2 & 0.2 & 0.1 & $1.5: 1: 1$ & 1.5 & 5.5 \\
\hline
\end{tabular}

(2) $\mathrm{HCl}$ concentration

\begin{tabular}{lccc} 
Sample & HCL conc. $(\mathrm{M})$ & IEC (meq/g) & Yield (g) \\
\hline S4 & 0 & 1.9 & 6.2 \\
S6 & 0.01 & 2.5 & 9.6 \\
S7 & 0.05 & 2.5 & 2.7 \\
S8 & 0.1 & 2.3 & 1.6 \\
S9 & 0.2 & 2 & 1.5 \\
S10 & 0.4 & 1.9 & 1 \\
S11 & 0.5 & No precipitate & - \\
\hline
\end{tabular}

(3) Gelation temperature

\begin{tabular}{lccc} 
Sample & Temperature $\left({ }^{\circ} \mathrm{C}\right)$ & IEC $(\mathrm{meq} / \mathrm{g})$ & Yield $(\mathrm{g})$ \\
\hline S6 & $25^{\circ} \mathrm{C}$ & 2.5 & 9.6 \\
S12 & $40^{\circ} \mathrm{C}$ & 2.35 & 8.6 \\
S13 & $50^{\circ} \mathrm{C}$ & 2.31 & 8.2 \\
S14 & $60^{\circ} \mathrm{C}$ & 2.25 & 8.6 \\
S15 & $80^{\circ} \mathrm{C}$ & 2.25 & 7.5 \\
\hline
\end{tabular}

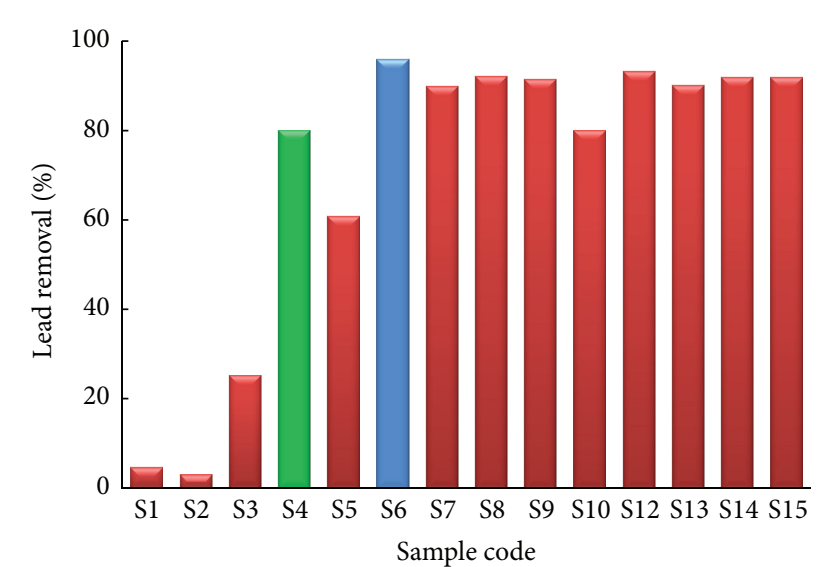

FIGURE 1: \% lead ion sorption using the different prepared samples produced from sol-gel technique.

3.1. Effect of Reactants Molar Ratio. The reactants molar ratio affected the ion exchange capacity of the prepared materials as seen in Table 1. It was obvious that the increment in zirconium and vanadate concentration in the reaction mixture enhanced the ion exchange capacity of the prepared material compared with the increase in tungstate ion concentration that has no effect on the IEC for the prepared material.
The EDX and ICP analysis of sample S4 that represented the most proper cation exchanger prepared sample investigated its chemical composition and were tabulated in Table 2. It is clear from this table that the ratio of anionic part represented by vanadate and tungstate ions in the ion exchanger is higher than that of cationic part represented by zirconium ions; this result confirms that the anionic part in the prepared ion exchange material is responsible for the ion exchange process inside the ion exchanger rather than the cationic part [17]. Accordingly, this prepared ion exchanger is characterized by its high ion exchange value, where the replacement $\mathrm{H}^{+}$ion inside the ion exchanger is associated with the anionic groups rather than the cationic one.

The sorption efficiency of the prepared materials was tested toward lead ions removal from synthetic wastewater. Sample S4 which has the highest IEC achieved the highest lead percentage removal compared to the other prepared samples as indicated in Figure 1. Consequently, on the basis of higher production yield, ion exchange capacity, and higher affinity for lead ions sorption compared to other prepared samples, the reactant molar ratio that produce sample $\mathrm{S} 4$ was utilized to optimize the remaining preparation parameters.

3.2. Effect of Hydrochloric Acid Concentration. Various samples of zirconium tungstovanadate ion exchanger were prepared using the predetermined optimum conditions of $0.2 \mathrm{M}$ 
TABLE 2: The molar composition of the prepared $\mathrm{Zr}(\mathrm{IV})$ tungstovanadate.

\begin{tabular}{lccc}
\hline Sample & $\begin{array}{c}\text { Preparation molar ratio } \\
(\mathrm{Zr}: \mathrm{V}: \mathrm{W})\end{array}$ & $\begin{array}{c}\text { EDX analysis } \\
(\mathrm{Zr}: \mathrm{V}: \mathrm{W})\end{array}$ & $\begin{array}{c}\text { ICP analysis } \\
(\mathrm{Zr}: \mathrm{V}: \mathrm{W})\end{array}$ \\
\hline S4 & $(2: 2: 1)$ & $(2: 1.8: 0.6)$ & $(2: 1.7: 0.6)$ \\
S5 & $(2: 1: 2)$ & $(2: 1: 0.4)$ & $(2: 1.1: 0.5)$ \\
\hline
\end{tabular}

$\mathrm{ZrOCl}_{2}, 0.2 \mathrm{M}$ ammonium metavanadate, and $0.1 \mathrm{M}$ sodium tungstate at different hydrochloric acid concentrations. The ion exchange capacities of the different prepared samples were tabulated in Table 1. It is evident from this table that the ion exchange capacity of the produced ion exchangers affected by $\mathrm{HCl}$ concentration present in the preparation media. The highest IEC value was recorded using $0.01 \mathrm{M}$ $\mathrm{HCl}$ (sample S6); this may be due to the presence of $\mathrm{HCl}$ which contributed to increasing the replacement hydrogen ions that present inside the produced ion exchangers structure. These structural hydrogen ions are responsible for the ion exchange process inside the prepared material. on the other hand, further increment in acid morality above $0.01 \mathrm{M}$ decline the ion exchange capacity of the prepared material. At the acidic molarity improved to $0.5 \mathrm{M}$, no precipitate has been formed. This results may be due to the improvement in the acidity of the reaction media above $0.01 \mathrm{M}$ dissolve some of the formed ion exchange materials. However, at $0.5 \mathrm{M}$ acidity, all produced exchanger powder materials have been dissolved immediately as formed.

The results obtained from testing the ion exchange efficiency of the prepared materials toward lead ions sorption are given in Figure 1, which indicated that sample S6 attained the highest \% lead sorption compared to the others. Finally, preparation parameters that produce sample S6 have been selected to optimize the remaining preparation conditions.

3.3. Effect of Gelation Temperature. The effect of gelation temperature was determined using $0.2 \mathrm{M} \mathrm{ZrOCl}_{2}, 0.2 \mathrm{M}$ ammonium metavanadate, and $0.1 \mathrm{M}$ sodium tungstate in presence of $0.01 \mathrm{M} \mathrm{HCl}$ at different temperatures. Table 1 investigated that the IEC of the prepared materials decreases with increasing gelation temperature, where the increment in the reaction temperature evaporated water from the reaction media that decreased the presence possibility of replacement hydrogen ions inside the exchanger which are responsible for the exchange process and accordingly decreased their IEC. So, the achievement of the sol-gel production process at mild temperatures is favourable to produce ion exchange material with high IEC.

Finally, after studying the preparation parameters using sol-gel technique, sample S6 that recorded the highest IEC $(2.5 \mathrm{meq} / \mathrm{g})$, the best production yield, and the highest lead percentage removal produced from the reaction of $0.2 \mathrm{M}$ $\mathrm{ZrOCl}_{2}, 0.01 \mathrm{M} \mathrm{HCl}, 0.1 \mathrm{M}$ sodium tungstate, and $0.2 \mathrm{M}$ ammonium metavanadate at $25^{\circ} \mathrm{C}$ was selected as the most proper prepared ion exchange sample produced from sol-gel technique to be fully characterized.
TABle 3: Comparison between the three different prepared zirconium tungstovanadate ion exchangers and those cation exchangers reported in the literature.

\begin{tabular}{lc}
\hline Ion exchange materials & (IEC) for $\mathrm{Na}^{+}$ \\
\hline Zirconium tungstovanadate(S6)(present study) & $\mathbf{2 . 5}$ \\
Zirconium vanadate [18] & 1.8 \\
Zirconium oxide [19] & 0.5 \\
Zirconium(IV) selenomolybdate [8] & 0.94 \\
Zr(IV) tungstomolybdate [5] & 2.4 \\
Zirconium iodovanadate [7] & 2.2 \\
Bismuth(iii) iodophosphate [20] & 0.5 \\
Titanium(IV) molybdophosphate [21] & 1.3 \\
\hline
\end{tabular}

3.4. Chemical Characterization. The best prepared sample was compared with the previously prepared comparable inorganic ion exchange materials and it was chemically characterized in terms of its chemical composition, in addition to its chemical and thermal stabilities.

3.4.1. Ion Exchange Capacity of the Prepared Cation Exchanger. The ion exchange of the most proper sol-gel prepared sample was compared with different comparable previously prepared inorganic ion exchange materials as investigated in Table 3.

3.4.2. Thermal Effects on Ion Exchange Capacity. Ion exchange capacity of the prepared material was affected by heating. On heating at different temperatures for $1 \mathrm{~h}$, the mass, physical appearance, and ion exchange capacity of the best prepared $\mathrm{Zr}$ (IV) tungstovanadate were changed as given in Table 4. One interesting property of nano-Zr (IV) tungstovanadate is distinguished by its thermal stability as the heating temperature incremented up to $700^{\circ} \mathrm{C}$.

3.4.3. Chemical Stability of Cation Exchanger. Results showing the extent of dissolution of the prepared materials in different solutions are given in Table 5. It is clear from the tabulated data that the prepared zirconium tungstovanadate cation exchanger is quite stable in water. This solubility experiments showed that the prepared material is highly chemically stable.

3.4.4. Physical Characterization. The X-ray diffraction pattern of the best prepared sample (S6) is shown in Figure 2. The X-ray diffraction spectrum shows a number of peaks at different $2 \theta$ values. The strong peaks intensities of these signals suggested that the nature of the prepared nano- $\mathrm{Zr}$ (IV) tungstovanadate is crystalline. The different intense peaks 
TABLE 4: Effect of temperature on the ion exchange capacity of $\mathrm{Zr}(\mathrm{IV})$ tungstovanadate on heating time for $1 \mathrm{~h}$.

\begin{tabular}{lccc}
\hline Heating temperature $\left({ }^{\circ} \mathrm{C}\right)$ & Appearance & IEC for $\mathrm{Na}^{+}$ion $\left(\mathrm{mequiv.g}^{-1}\right)$ & \% loss in IEC \\
\hline 50 & Yellow & 2.5 & 0 \\
100 & Yellow & 2.45 & 2 \\
200 & Yellow & 2.39 & 4.4 \\
400 & Yellow & 2.25 & 10 \\
500 & Dark yellow & 2.15 & 16 \\
600 & Dark yellow & 1.8 & 28 \\
700 & Greenish yellow & 1.6 & 36 \\
\hline
\end{tabular}

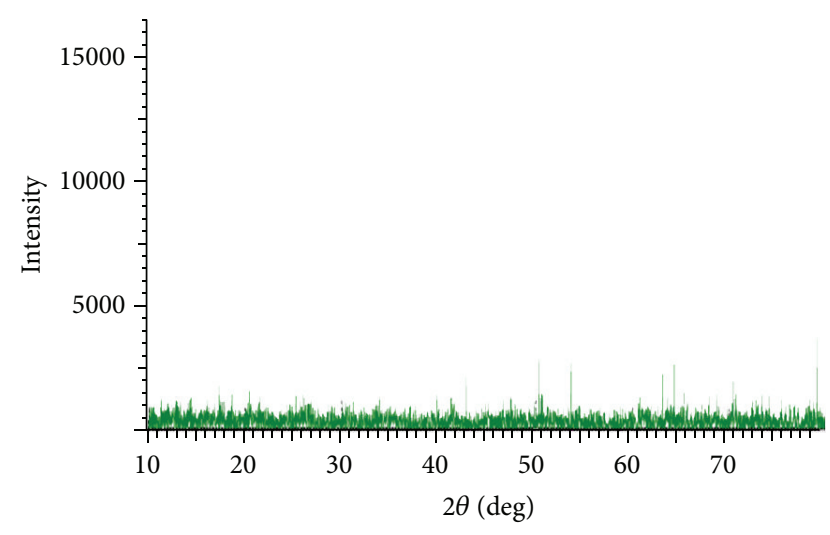

Figure 2: X-ray curve for zirconium tungstovanadate.

TABLE 5: Solubility of $\mathrm{Zr}(\mathrm{IV})$ tungstovanadate in various solvents ( $0.5 \mathrm{~g}$ of the material was initially taken for the treatment).

\begin{tabular}{lcc}
\hline Solution & Wt. after treatment $(\mathrm{g})$ & ${\text { IEC for } \mathrm{Na}^{+}(\mathrm{meq} / \mathrm{g})}$ \\
\hline Acids & & \\
$0.1 \mathrm{M} \mathrm{HCl}$ & 0.5 & 2.5 \\
$0.5 \mathrm{M} \mathrm{HCl}$ & 0.5 & 2.5 \\
$2 \mathrm{M} \mathrm{HCl}$ & 0.5 & 2.5 \\
$5 \mathrm{M} \mathrm{HCl}$ & 0.48 & 2.1 \\
$\mathrm{HNO}_{3}$ & 0.2 & 1.5 \\
$\mathrm{H}_{2} \mathrm{SO}_{4}$ & 0.32 & 1.9 \\
Organic solvents & & \\
Benzene & 0.5 & 2.5 \\
Heptane & 0.5 & 2.5 \\
Acetone & 0.5 & 2.5 \\
Isopropanol & 0.5 & 2.5 \\
Diethyl ether & 0.5 & 2.5 \\
Bases & & \\
$1 \mathrm{M} \mathrm{KOH}$ & 0.45 & 1.92 \\
$1 \mathrm{M} \mathrm{NaOH}$ & 0.4 & 1.8 \\
\hline
\end{tabular}

presented in the sample were compared with that in the two references of zirconium oxide phases (card number. 01-0871528) and (number. 01-088-0586) in order to determine the plane orientation of the cation exchange sample produced (Table 6). It was clear from the table that the produced sample represents a mixture of zirconium tungsten oxide and zirconium vanadium oxide with cubic crystal configurations.
TABLE 6: X-ray peak values for two reference phases.

\begin{tabular}{lcc}
\hline Reference & $2 \theta$ for strain & Plan of orientation \\
\hline $\begin{array}{l}\text { 2 } \theta \text { for cubic zirconium tungsten oxide reference } \\
\text { (card no. 01-087-1528) }\end{array}$ & $(331)$ \\
43.0067 & 43.1740 & $(521)$ \\
54.842 & 54.2545 & $(541)$ \\
66.0471 & 65.9729 & $(722)$ \\
78.8197 & 78.6726 & \\
$2 \theta$ for cubic zirconium vanadium oxide reference \\
(card no. 01-088-0586) \\
17.4341 & 17.7839 & $(111)$ \\
51.8902 & 51.6046 & $(430)$ \\
62.351 & 62.9232 & $(135)$ \\
\hline
\end{tabular}

According to the TGA analysis given in Figure 3, patterns of the prepared zirconium tungstovanadate sample show two main weight losses or degradation regions. The first weight loss region is maximum at around $140^{\circ} \mathrm{C}$ which is due to the free external water molecules removal [22], while the second gradual loss in the samples weight that began from temperatures above $370^{\circ} \mathrm{C}$ is due to the removal of interstitial water molecules by condensation of exchangeable hydroxyl groups $(-\mathrm{OH})$ from the material, which is characteristic of synthetic inorganic ion exchangers [23]. Above $450^{\circ} \mathrm{C}$ there is no significant degradation, which means that no structural changes can occur for the materials. This suggests that the prepared ion exchanger is stable up to $800^{\circ} \mathrm{C}$.

Morphological characterization of the prepared cation exchanger zirconium tungstovanadate was performed using SEM. Figure 4 indicates that the selected sample shows average diameter $0.028 \mathrm{~nm}$. Thus, the produced cation exchange material has been prepared in the nanorange.

The FTIR spectra of the selected cation exchange zirconium tungstovanadate sample are showed in Figure 5. The analysis of its absorption peaks is investigated in Table 7. The appearance of the peaks has been designated accordingly [24]. This analysis assigns the presence of structural $\mathrm{H}-\mathrm{OH}$ that is responsible mainly for the exchangeable $\mathrm{H}^{+}$ion inside the prepared nanocation exchange sample. Moreover, it was confirmed from the characteristics peaks analysis that the materials are composed mainly of a mixture of zirconium tungsten oxide and zirconium vanadium oxide as stated previously in XRD section. 


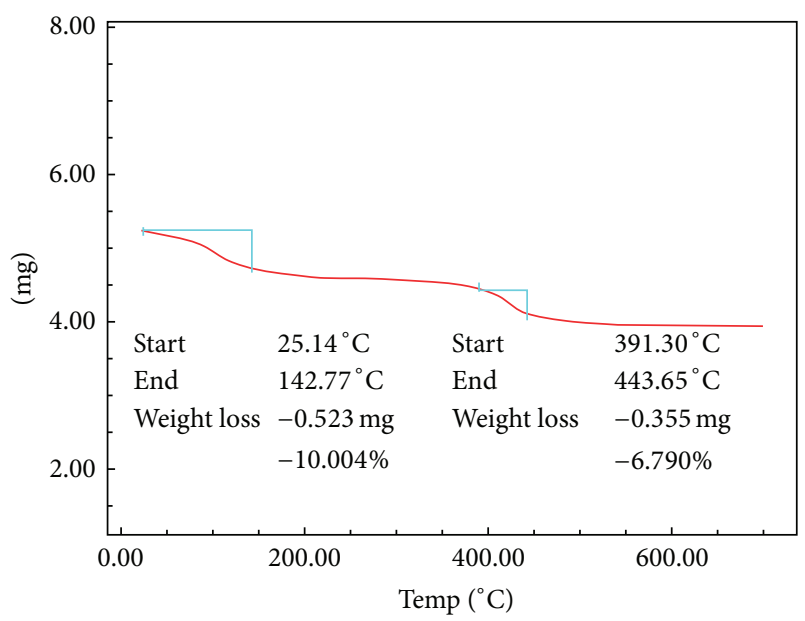

FigURE 3: TGA curve for nanozirconium tungstovanadate.

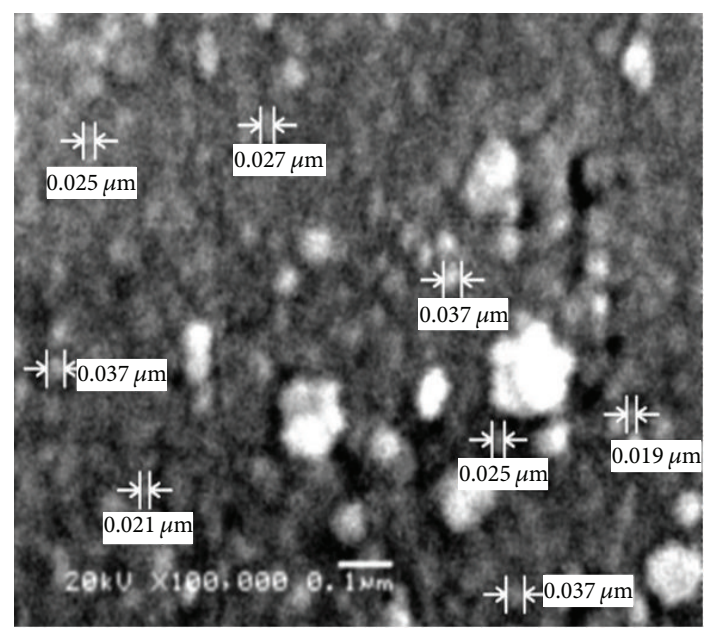

FIGURE 4: SEM micrograph of prepared zirconium tungstovanadate.

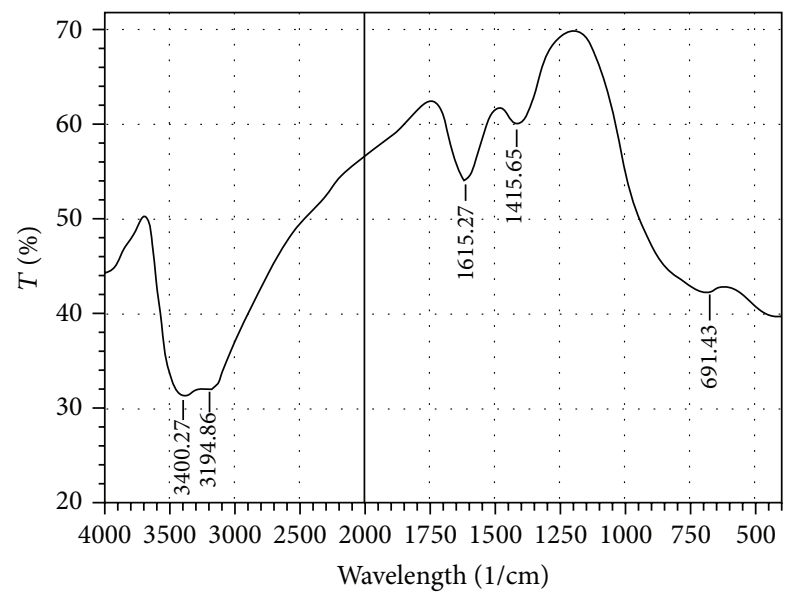

FIGURE 5: FTIR spectra of Zr(IV) tungstovanadate cation exchanger.
TABLE 7: Details of IR spectrum of nano-zirconium tungstovanadate.

\begin{tabular}{lc}
\hline Wave number $\left(\mathrm{cm}^{-1}\right)$ & Significance \\
\hline $3000-3500$ & $\begin{array}{c}\text { Hydroxostretcing vibrations (-OH } \\
\text { groups) }\end{array}$ \\
$1600-1630$ & $\begin{array}{c}\text { Deformation vibrations of coordinated } \\
\text { water (H-O-H bonding) }\end{array}$ \\
$1400-1420$ & Vibrations due to metal hydroxyl groups \\
& $(\mathrm{M}-\mathrm{OH})$ \\
$600-750$ & $\begin{array}{c}\text { Superposition of metal oxygen stretching } \\
\text { vibrations (W-O, Zr-O, V-O). }\end{array}$ \\
\hline
\end{tabular}

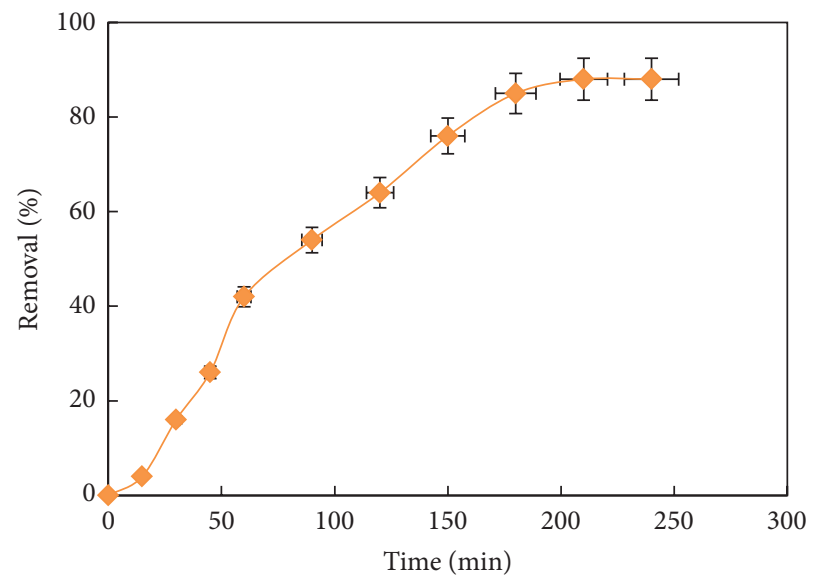

FIGURE 6: Effect of contact time on the sorption of $\mathrm{pb}^{2+}$ by zirconium tungstovanadate (initial lead conc. $=500 \mathrm{ppm}$; resin dose $=0.25 \mathrm{~g}$; solution volume $=100 \mathrm{~mL}$, temperature $=25 \pm 2^{\circ} \mathrm{C}$; agitation speed $=200 \mathrm{rpm} ; \mathrm{pH}=7$ ).

\subsection{Batch Experiments for Lead Ion Separation}

(a) Effect of Contact Time. The effect of contact time on the lead ions sorption onto nanozirconium tungstovanadate was investigated in Figure 6. This figure elucidated that the percentage lead removal increases with contact time and attains equilibrium within $3 \mathrm{hr}$; this effect has arisen from the fact that heavy metal-zirconium tungstovanadate interaction is a dynamic process and the amount of metal uptake is a function of time [25]. Thus, $3 \mathrm{hr}$ is chosen as the reaction time required for equilibrium achievement for the lead ion sorption process.

(b) Effect of Ion Exchanger Dose. The exchanger amount is an essential parameter to obtain the quantitative uptake of metal ion. Different amounts of the ion exchanger were tested in the range of $0.1-5 \mathrm{~g}$ and equilibrated for $3 \mathrm{~h}$ at an initial lead concentration of $500 \mathrm{ppm}$; all experiments were carried out at the same stirring speed, $200 \mathrm{rpm}$. The lead ion removal results are given in Figure 7. It is apparent that sorption of lead ions was increased sharply as the cation exchange amount improved up to $2 \mathrm{~g}$. This result was expected because, for a fixed initial metal concentration, increasing adsorbent amount provides greater surface area and sorption sites for metal ions uptake that by its role enhanced the metal ion 


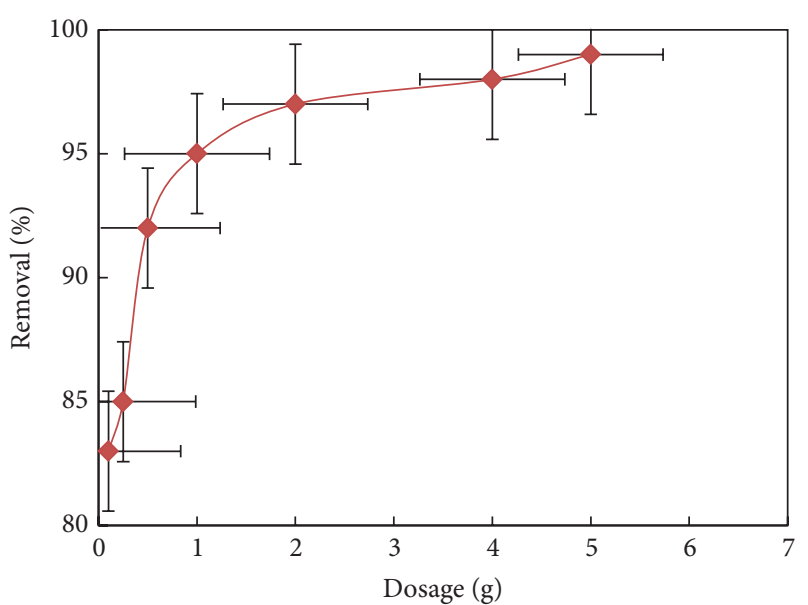

FIGURE 7: Effect of cation exchange dosage on the sorption of $\mathrm{Pb}^{2+}$ ions (initial lead concentration $=500 \mathrm{ppm}$; solution volume $=$ $100 \mathrm{~mL}$, temperature $=25 \pm 2^{\circ} \mathrm{C}$; Agitation speed $=200 \mathrm{rpm} ; \mathrm{pH}=$ 7).

removal [26, 27]. It is readily understood that the number of available sorption sites increases by increasing the cation exchanger amount. However, further improvement in the ion exchange amount above $2 \mathrm{~g}$ declined the increment rate in the lead ion removal as presented in Figure 7. This may be regarded to the improvement in the available active sites at the ion exchange material in spite of the fixation of the lead ions available to be removed. Accordingly, as the material dose incremented above $2 \mathrm{~g}$, the number of unoccupied. Finally, the optimum cation exchanger dosage that record the optimum lead ion removal value of $97 \%$ was assigned as $2 \mathrm{gm}$.

(c) Effect of Initial Metal Concentration. Predetermined optimal values of nanozirconium tungstovanadate dosage were used for examining effects of lead ion concentration on the lead removal process. Figure 8(a) illustrated that the removal percentage of lead ions decreases with increasing initial $\mathrm{Pb}^{+2}$ concentrations. The decrease in the rate of $\mathrm{Pb}^{2+}$ removal with increasing initial concentration may be attributed to the increase in the repulsion forces between the same charged species with increasing the metal ion concentration. Thus, this will hinder the mobility of metal ion toward the exchangeable sites [28, 29]. However, Figure 8(b) presented that the lead ions sorption capacities of the ion exchange material increased as the lead ion concentration improved. So, the lead ions sorption capacity has reversible behaviour than the lead ion percentage removal. This behaviour may be attributed to the fact that concentration provides an important driving force to overcome all mass transfer resistance of the lead ions between the aqueous and solid phases. Hence, a higher initial concentration of lead ions will enhance the sorption process. Moreover, the increment in lead ion sorption capacity with the improvement opposed that at low ions concentration there are a large number of unoccupied active sites onto the prepared that decrease its sorption capacity, as the ion concentration improved its capacity was

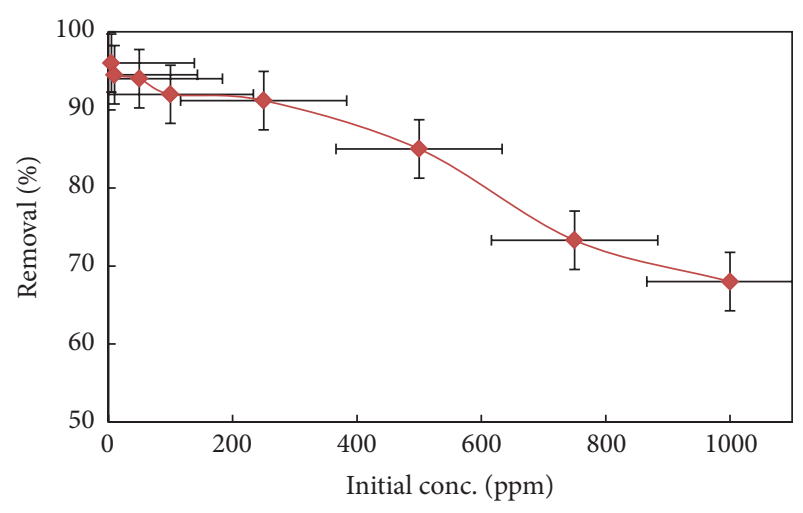

(a)

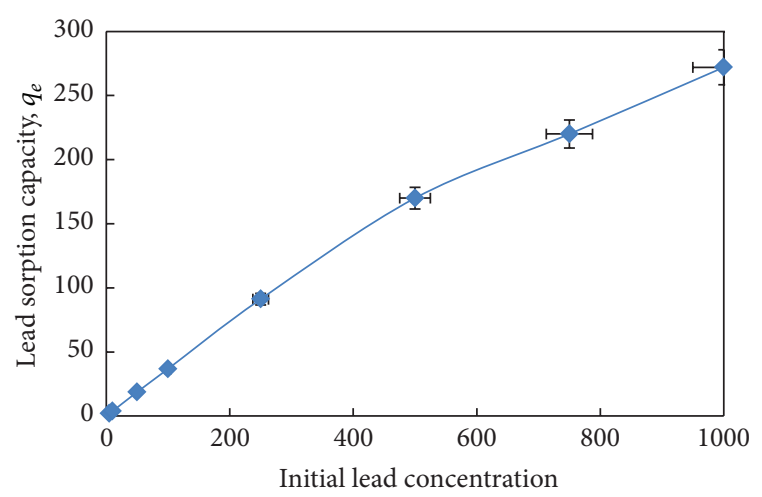

(b)

FIGURE 8: Effect of initial metal concentration on the ion exchange of $\mathrm{Pb}^{2+}$ ions using the prepared cation exchanger (exchanger dosage $=$ $0.25 \mathrm{~g}$; volume of solution $=100 \mathrm{~mL}$, temperature $=25 \pm 2^{\circ} \mathrm{C}$; agitation speed $=200 \mathrm{rpm} ; \mathrm{pH}=7$ ).

improved due to the improvement of the number of working active sites.

(d) Effect of $p H$. Hydronium ion concentration is an important parameter affecting the ion exchange process. This is partly because hydrogen ions themselves are strongly competing adsorbate. In order to investigate the effect of $\mathrm{pH}$ on lead removal using the prepared nanozirconium, experiments were performed in the $\mathrm{pH}$ range (1-11). As seen from Figure 9 optimal uptake of $\mathrm{Pb}^{2+}$ occurred at $\mathrm{pH}$ range of 5-7. At high $\mathrm{pH}$ values, decrease in removal efficiency achieved by nanozirconium tungstovanadate can be described with formation of $\mathrm{Pb}(\mathrm{OH})_{2}$ during reaction of $\mathrm{Pb}^{2+}$ ions with $\mathrm{OH}^{-}$. In this state, hydrolysis accompanied by precipitation of metal hydroxides may occur [26]. However, at low $\mathrm{pH}$ values, the decrease in lead ion removal may be returned to the competition of $\mathrm{H}^{+}$ions with $\mathrm{Pb}^{2+}$ in the ion exchange process onto the prepared cation exchanger.

(e) Effect of Solution Temperature. The effect of temperature on the ion exchange process is important not only because it affects the rate and extent of sorption but also due to the fact that temperature dependence of sorption provides information about possible sorbate-sorbent interaction [30]. 


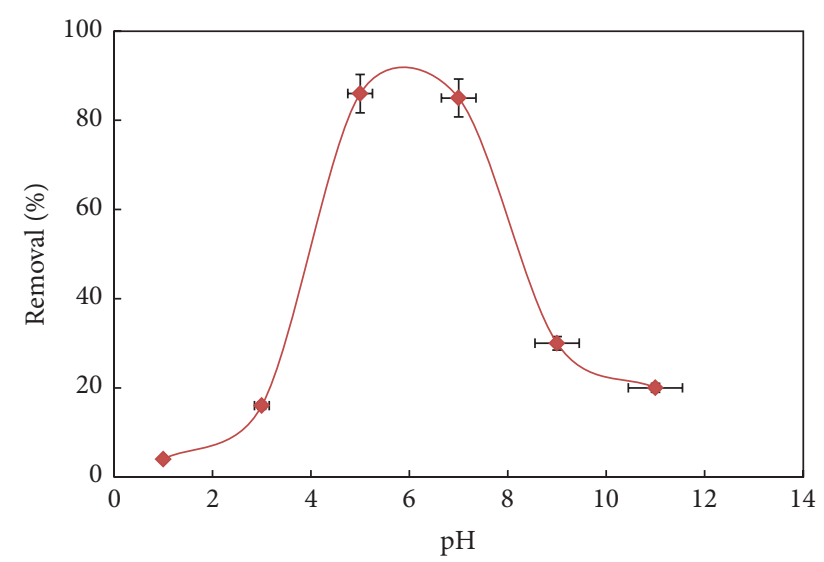

FIgURE 9: Effect of initial solution $\mathrm{pH}$ on the ion exchange of $\mathrm{Pb}^{2+}$ ions (exchanger dosage $=0.25 \mathrm{~g}$; solution volume $=100 \mathrm{~mL}$, temperature $=25 \pm 2^{\circ} \mathrm{C}$; agitation speed $=200 \mathrm{rpm}$; initial lead conc. $=500 \mathrm{ppm})$.

In the temperature range of $25-80 \circ \mathrm{C}$, the removal capacity of the prepared inorganic ion exchanger for the lead ions was determined. From Figure 10 it is clear that lead ions removal from the aqueous solution increased with raising temperature. It may be returned to the fact that higher temperatures activate the lead ions for enhancing sorption at the coordinating sites of nanocation exchanger. Also, it is mentioned that cations move faster when temperature increases. Potential explanations for this are that specific or electrostatic interactions become weaker and the ions become smaller, since solvation is reduced [31]. This result indicates that the ion exchange process is an endothermic process onto the prepared nanozirconium tungstovanadate.

3.6. Adsorption Isotherms. Results obtained for lead ions sorption using the prepared nanozirconium tungstovanadate were analyzed with well-known adsorption models, Langmuir and Freundlich.

3.6.1. Langmuir Model. The Langmuir isotherm is a commonly applied model for adsorption on a completely homogenous surface with negligible interaction between adsorbed molecules [32]. The model assumes uniform adsorption energies onto the surface and maximum adsorption depends on saturation level of monolayer. Langmuir model can be represented with the following linear equation:

$$
\frac{C_{e}}{q_{e}}=\frac{1}{k q_{m}}+\frac{C_{e}}{q_{m}},
$$

where $q_{e}$ represents the mass of adsorbed lead per unit cation exchanger $(\mathrm{mg} / \mathrm{g}), q_{m}$ is the monolayer capacity, $k$ is the equilibrium constant, and $C_{e}$ is the equilibrium concentration of the solution $(\mathrm{mg} / \mathrm{L})$. Plot of $C_{e} / q_{e}$ versus $C_{e}$ should indicate a straight line of slope $1 / q_{m}$ and an intercept of $1 / q_{m} k$. Figure 11 investigates that the Langmuir equation represents the sorption process of lead ions at the prepared nanozirconium tungstovanadate ion exchanger very well. The

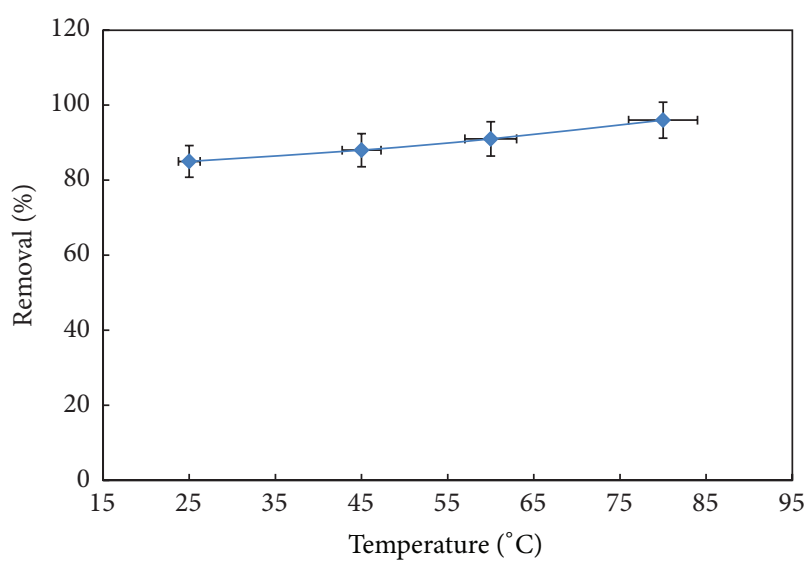

FIGURE 10: Effect of solution temperature on lead removal at equilibrium using the prepared cation exchanger (initial lead conc. $=500 \mathrm{ppm}$, ion exchanger dosage $=0.25 \mathrm{~g}$, agitation time $=3 \mathrm{~h}$, agitation speed $=200 \mathrm{rpm}$, solution volume $=100 \mathrm{~mL}$, and $\mathrm{pH}=7$ ).

applicability of this model gives predication that the main mechanism for lead ions separation using the synthesized material may take place through the ion exchange process as monolayer at the ion exchange material. The Langmuir parameters for lead ions removal, $q_{m}$ and $k$, were calculated from the slope and intercept of these figures and tabulated in Table 7. The maximum monolayer sorption capacity for lead ions onto the prepared nano-cation exchanger was equals to $250 \mathrm{mg} / \mathrm{g}$. So, the prepared nanomaterial is distinguished by its high lead ion sorption capacity. Accordingly, it is suitable to be utilized for industrial wastewater treatment processes.

3.6.2. Freundlich Model. The Freundlich model is known as the earliest empirical equation and is shown to be consistent with exponential distribution of active centers, characteristic of heterogeneous surfaces $[31,32]$. Freundlich equation is

$$
\log q_{e}=\log k_{f}+\frac{1}{n} \log C_{e}
$$

where $k_{f}$ and $n$ represent adsorption capacity and intensity, respectively. $k_{f}$ is an important constant used as relative measure for adsorption efficiency. The magnitude of the $n$ shows an indication of the favourability of adsorption. Values of $n$ larger than 1 show the favorable nature of adsorption $[33,34]$. The plot of $\ln q_{e}$ against $\ln C_{e}$ for lead ions sorption data on the prepared nanocation exchanger is fitting well to the Freundlich isotherm (Figure 12). Accordingly, the lead ion sorption onto the prepared nanocation exchanger may be described by both Langmuir and Freundlich isotherm models. However, the Langmuir applicability for the lead sorption process is much higher than the Freundlich applicability according to the models correlation coefficient values. This gives prediction that the adsorption phenomena have some degree of contribution besides the ion exchange mechanism in lead ions separation. The $n$ value that is equal to $1.75(n>1)$ confirms the favourability nature of lead ion sorption onto the prepared nanomaterials. 


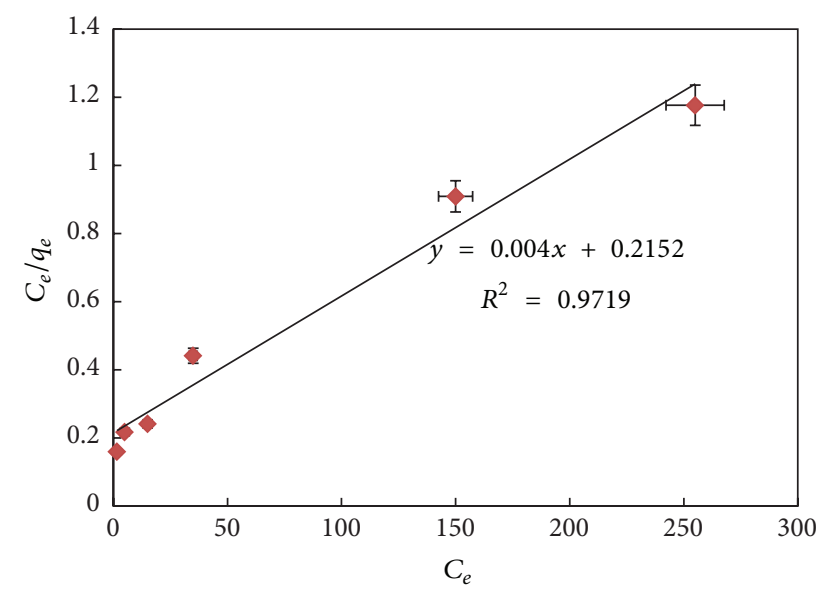

FIGURE 11: Langmuir adsorption isotherm for lead sorption using nanozirconium tungstovanadate.

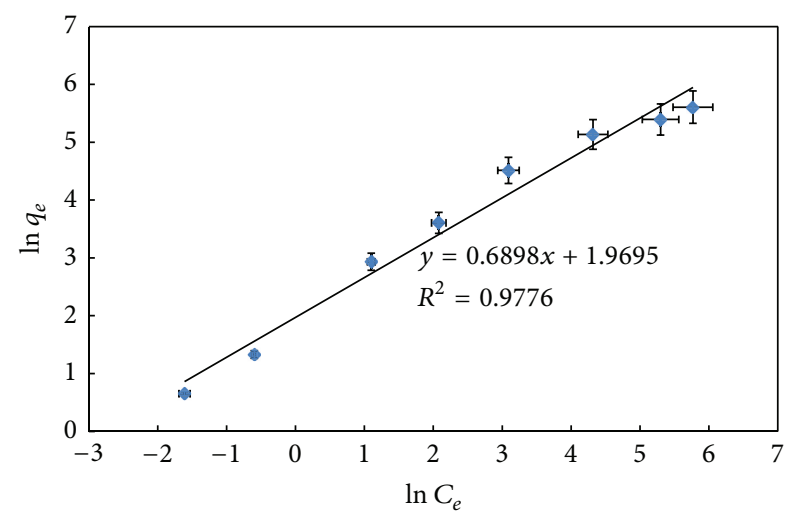

FIGURE 12: Freundlich adsorption isotherm for lead ions sorption on nano-zirconium tungstovanadate.

\section{Conclusion}

New nanozirconium(IV) tungstovanadate ion exchanger was synthesized successfully using sol-gel technique and characterized and its analytical application was explored. The optimum preparation conditions which produce the most proper ion exchanger that is characterized by its high IEC and lead ion sorption capacity were $0.2 \mathrm{M} \mathrm{ZrOCl}_{2}, 0.01 \mathrm{M} \mathrm{HCl}$, $0.1 \mathrm{M}$ sodium tungstate, and $0.2 \mathrm{M}$ ammonium metavanadate at $25^{\circ} \mathrm{C}$. This sample recorded the highest IEC value of 2.5 $\mathrm{meq} / \mathrm{g}$ compared with the other sol-gel prepared samples. The XRD spectrum of this best ion exchange sample S6 indicated that it has crystalline structure. Moreover, the SEM imaging confirms that they were prepared in nanostructure. The material is fairly stable in inorganic acids, bases, and organic solvents. The promising feature of the material is its affinity for $\mathrm{Pb}^{2+}$ ions, which is one of the most toxic metal ions present in the environment.

By studying Langmuir and Freundlich, it was clear that the sorption of lead ions by the prepared zirconium tungstovanadate ion exchanger seemed to involve adsorption phenomenon in addition to ion exchange process.

\section{Conflict of Interests}

The authors declare that there is no conflict of interests regarding the publication of this article.

\section{Acknowledgments}

This work was supported by two grants from the Academy of Scientific Research and Technology (Grant no. C31) and the Egyptian Science and Technology Development fund (STDF) (Grant no. 5546).

\section{References}

[1] F. Gode and E. Pehlivan, "A comparative study of two chelating ion-exchange resins for the removal of chromium(III) from aqueous solution," Journal of Hazardous Materials, vol. 100, no. 1-3, pp. 231-243, 2003.

[2] N. H. Shaidan, U. Eldemerdash, and S. Awad, "Removal of $\mathrm{Ni}(\mathrm{II})$ ions from aqueous solutions using fixed-bed ion exchange column technique," Journal of the Taiwan Institute of Chemical Engineers, vol. 43, no. 1, pp. 40-45, 2012.

[3] S. H. Jang, B. G. Min, Y. G. Jeong, W. S. Lyoo, and S. C. Lee, "Removal of lead ions in aqueous solution by hydroxyapatite/polyurethane composite foams," Journal of Hazardous Materials, vol. 152, no. 3, pp. 1285-1292, 2008.

[4] J. Krtil, "Exchange properties of ammonium salts of 12heteropolyacids-II: separation of rubidium and caesium on ammonium phosphotungstate," Journal of Inorganic and Nuclear Chemistry, vol. 19, pp. 298-303, 1961.

[5] S. A. Nabi, M. Naushad, and I. Inamuddin, "Synthesis and characterization of a new inorganic cation-exchanger- $\mathrm{Zr}(\mathrm{IV})$ tungstomolybdate: analytical applications for metal content determination in real sample and synthetic mixture," Journal of Hazardous Materials, vol. 142, no. 1-2, pp. 404-411, 2007.

[6] W. A. Siddiqui and S. A. Khan, "Synthesis, characterization and ion exchange properties of zirconium(IV) tungstoiodophosphate, a new cation exchanger," Bulletin of Materials Science, vol. 30, no. 1, pp. 43-49, 2007.

[7] P. Singh, J. P. Rawat, and N. Rahman, "Synthesis and characterization of zirconium(IV) iodovanadate and its use as electron exchanger," Talanta, vol. 59, no. 3, pp. 443-452, 2003.

[8] A. P. Gupta, G. L. Verma, and S. Ikram, "Studies on a new heteropolyacid-based inorganic ion exchanger; Zirconium(IV) selenomolybdate," Reactive and Functional Polymers, vol. 43, no. 1, pp. 33-41, 2000.

[9] R. Thakkar and U. Chudasama, "Synthesis and characterization of zirconium titanium phosphate and its application in separation of metal ions," Journal of Hazardous Materials, vol. 172, no. 1, pp. 129-137, 2009.

[10] S. A. Nabi, A. Alimuddin, and A. Islam, "Synthesis and characterization of a new cation exchangerzirconium(IV)iodotungstate: separation and determination of metal ion contents of synthetic mixtures, pharmaceutical preparations and standard reference material," Journal of Hazardous Materials, vol. 172, no. 1, pp. 202-207, 2009.

[11] P. Sharma and N. Neetu, "Synthesis, characterization and sorption behavior of zirconium(IV)antimonotungstate: an inorganic ion exchanger," Desalination, vol. 267, no. 2-3, pp. 277-285, 2011. 
[12] R. R. Shehaa and S. H. El-Khouly, "Adsorption and diffusion of cesium ions in zirconium(IV) iodomolybdate exchanger," Chemical Engineering Research and Design, vol. 9, pp. 942-954, 2013.

[13] M. M. Abd El-Latif and M. F. El-Kady, "Developing and characterization of a new zirconium vanadate ion exchanger and its novel organic-inorganic hybrid," Journal of Applied Sciences Research, vol. 4, pp. 1-13, 2008.

[14] K. Roy, P. K. Mohapatra, N. Rawat, D. K. Pal, S. Basu, and V. K. Manchanda, "Separation of $90 \mathrm{Y}$ from $90 \mathrm{Sr}$ using zirconium vanadate as the ion exchanger," Applied Radiation and Isotopes, vol. 60 , no. 5, pp. 621-624, 2004.

[15] M. M. Abd El-Latif and M. F. Elkady, "Synthesis, characterization and evaluation of nano-zirconium vanadate ion exchanger by using three different preparation techniques," Materials Research Bulletin, vol. 46, no. 1, pp. 105-118, 2011.

[16] I. Inamuddin, S. A. Khan, W. A. Siddiqui, and A. A. Khan, "Synthesis, characterization and ion-exchange properties of a new and novel "organic-inorganic" hybrid cation-exchanger: nylon-6,6, Zr(IV) phosphate," Talanta, vol. 71, no. 2, pp. 841847, 2007.

[17] S. A. Nabi, M. Naushad, and I. Inamuddin, "Synthesis and characterization of a new inorganic cation-exchanger-Zr(IV) tungstomolybdate: analytical applications for metal content determination in real sample and synthetic mixture," Journal of Hazardous Materials, vol. 142, no. 1-2, pp. 404-411, 2007.

[18] M. Qureshi, N. Zehra, S. A. Nabi, and V. Kumar, "Comparative study of titanium(IV)-based exchangers in aqueous and mixed solvent systems," Talanta, vol. 20, no. 7, pp. 609-620, 1973.

[19] S. Chand, Seema, Arti, and C. V. Chahal, "Synthesis, characterization and ion exchange properties of a new ion exchange material: bismuth (iii) Iodophosphate," Recent Research in Science and Technology, vol. 3, no. 6, pp. 1-8, 2011.

[20] R. Yavari, S. J. Ahmadi, Y. D. Huang, A. R. Khanchi, G. Bagheri, and J. M. He, "Synthesis, characterization and analytical application of a new inorganic cation exchanger-Titanium(IV) molybdophosphate," Talanta, vol. 77, no. 3, pp. 1179-1184, 2009.

[21] R. Yavari, S. J. Ahmadi, Y. D. Huang, A. R. Khanchi, G. Bagheri, and J. M. He, "Synthesis, characterization and analytical application of a new inorganic cation exchanger-Titanium(IV) molybdophosphate," Talanta, vol. 77, no. 3, pp. 1179-1184, 2009.

[22] C. Duval, Inorganic Thermogravimetric Analysis, Elsevier, Amsterdam, The Netherlands, 1963.

[23] G. Socrates, Infrared Characteristic Group Frequencies, John Wiley and Sons, New York, NY, USA, 1980.

[24] M. Davis, Infrared Spectroscopy and Molecular Structure, Elsevier, Amsterdam, The Netherlands, 1963.

[25] F. A. Miller and C. H. Wilkins, "Infrared spectra and characteristic frequencies of inorganic ions: their use in qualitative analysis," Analytical Chemistry, vol. 24, no. 8, pp. 1253-1294, 1952.

[26] D. Liaoa, W. Zhengb, X. Li et al., "Removal of lead(II) from aqueous solutions using carbonate hydroxyapatite extracted from eggshell waste," Journal of Hazardous Materials, vol. 177, pp. 126-130, 2010.

[27] Y. S. Ho and G. McKay, "The kinetics of sorption of divalent metal ions onto sphagnum moss peat," Water Research, vol. 34, no. 3, pp. 735-742, 2000.

[28] B. Alyüz and S. Veli, "Kinetics and equilibrium studies for the removal of nickel and zinc from aqueous solutions by ion exchange resins," Journal of Hazardous Materials, vol. 167, no. 1-3, pp. 482-488, 2009.
[29] M. M. Abd El-Latif and M. F. Elkady, "Equilibrium isotherms for harmful ions sorption using nano zirconium vanadate ion exchanger," Desalination, vol. 255, no. 1-3, pp. 21-43, 2010.

[30] A. K. Bajpai and N. Vishwakarma, "Adsorption of polyvinylalcohol onto Fuller's earth surfaces," Colloids and Surfaces A, vol. 220, no. 1-3, pp. 117-130, 2003.

[31] R. Naseem and S. S. Tahir, "Removal of $\mathrm{Pb}(\mathrm{II})$ from aqueous/acidic solutions by using bentonite as an adsorbent," Water Research, vol. 35, no. 16, pp. 3982-3986, 2001.

[32] F. Gode and E. Pehlivan, "Adsorption of Cr(III) ions by Turkish brown coals," Fuel Processing Technology, vol. 86, no. 8, pp. 875884, 2005.

[33] Y.-S. Ho, "Effect of $\mathrm{pH}$ on lead removal from water using tree fern as the sorbent," Bioresource Technology, vol. 96, no. 11, pp. 1292-1296, 2005.

[34] E. V. Veliev, T. Öztürk, S. Veli, and A. G. Fatullayev, "Application of diffusion model for adsorption of azo reactive dye on pumice," Polish Journal of Environmental Studies, vol. 15, no. 2, pp. 347-353, 2006. 

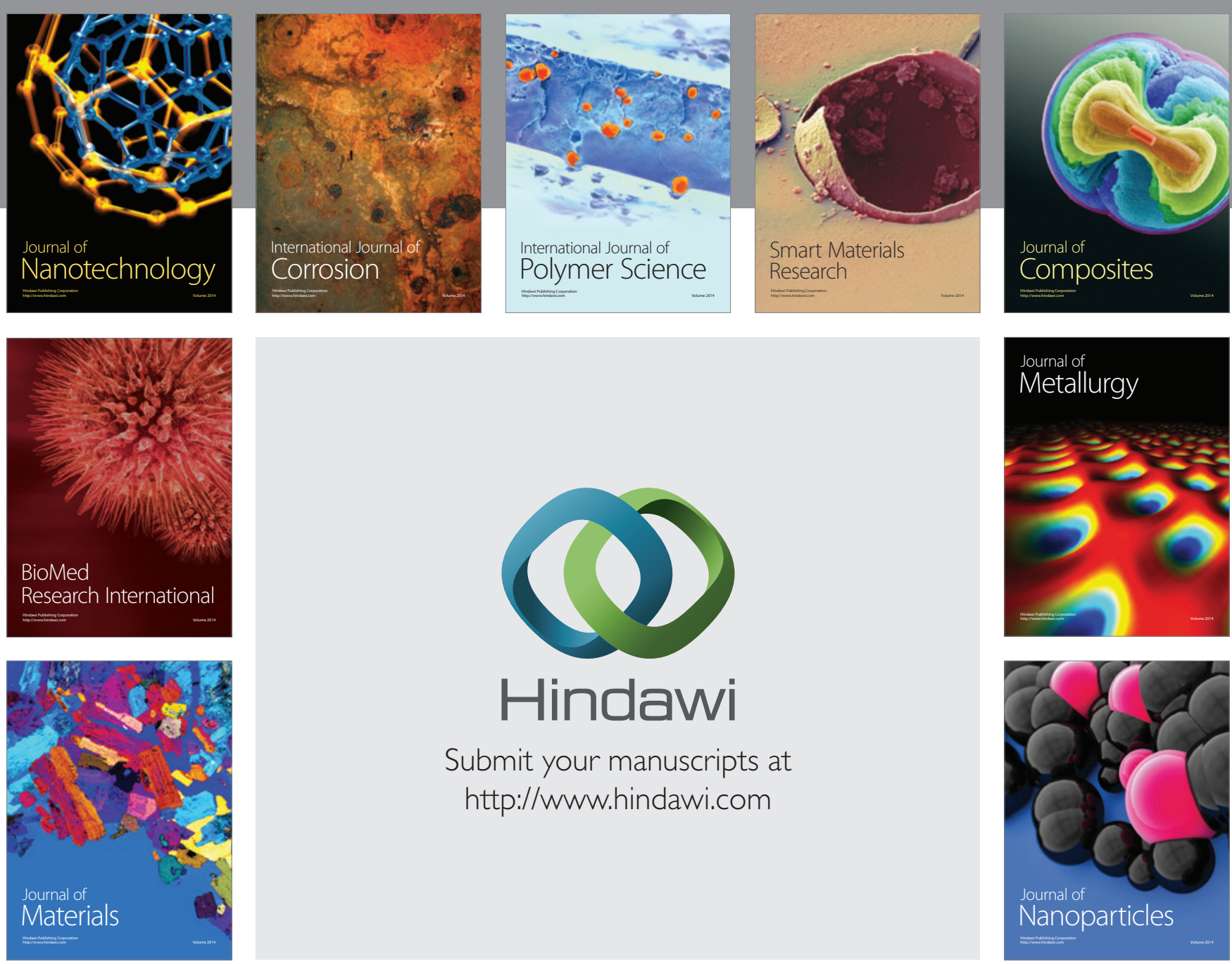

Submit your manuscripts at http://www.hindawi.com
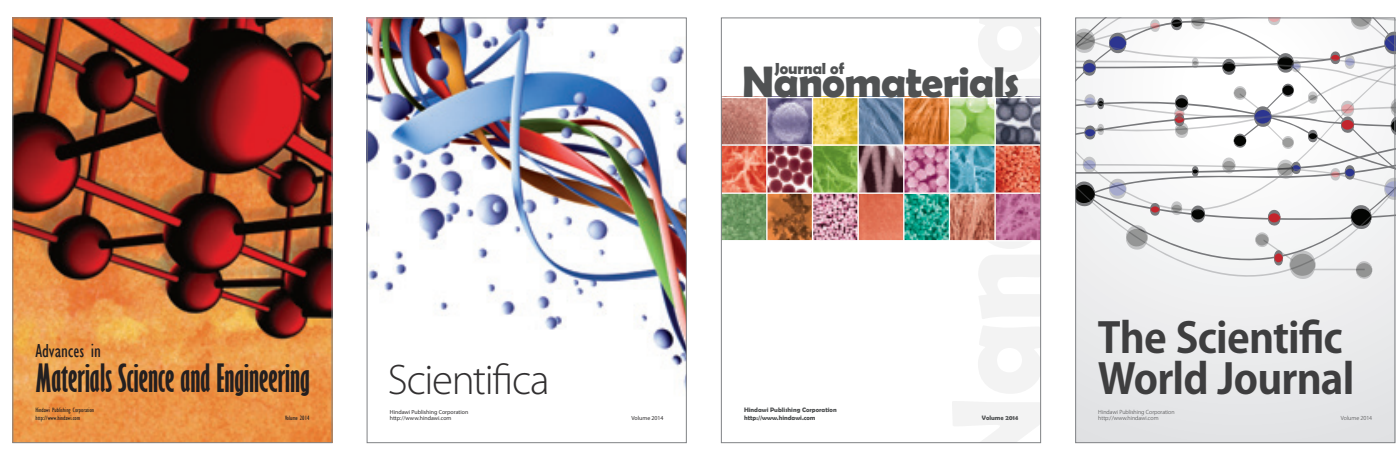

\section{The Scientific World Journal}
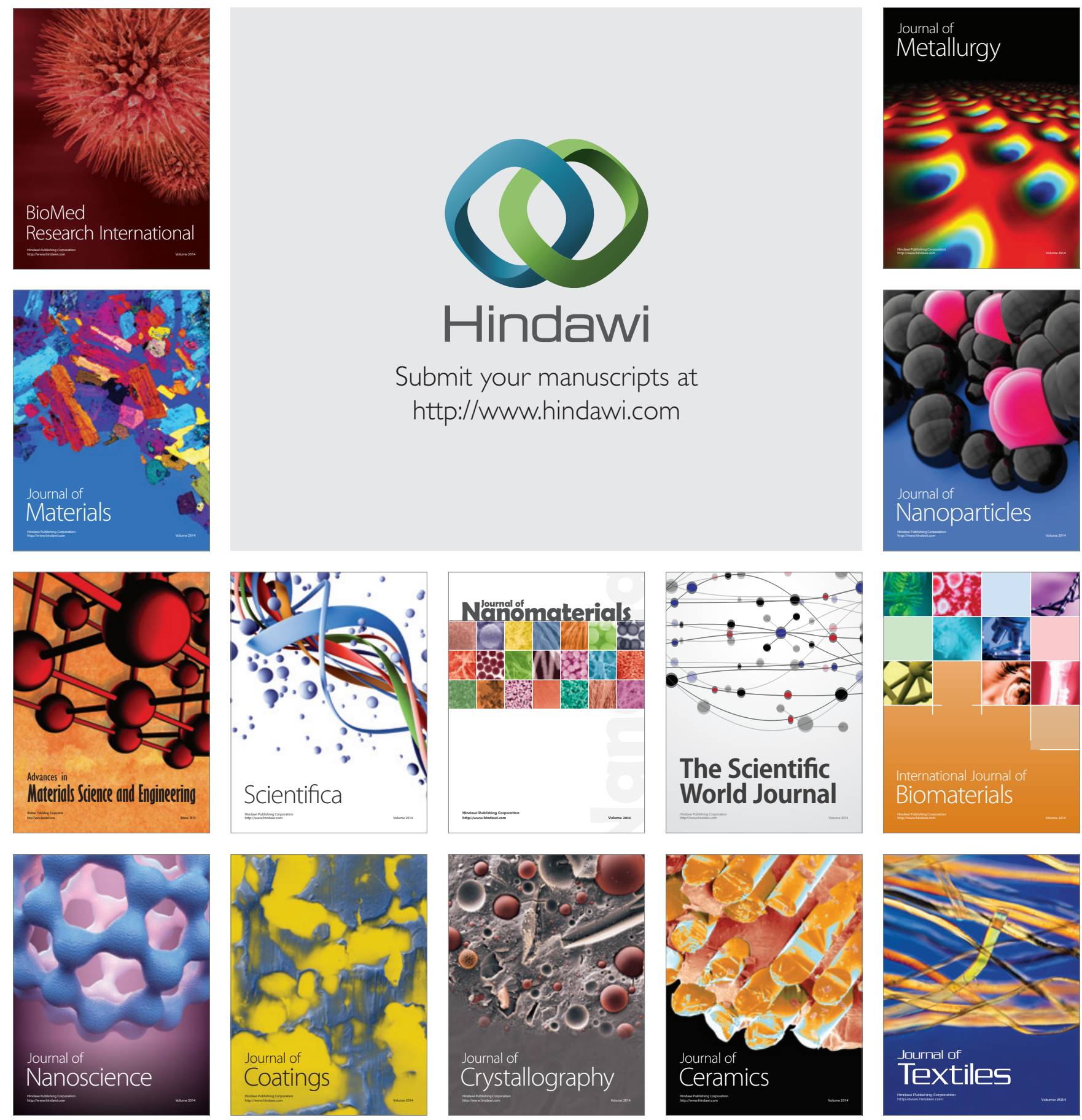